\title{
Overexpression of integrin-linked kinase induces cardiac stem cell expansion
}

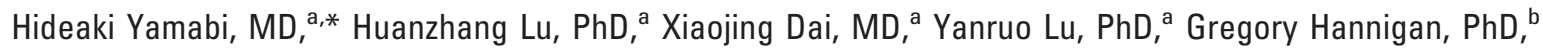
and John G. Coles, MD ${ }^{a, *}$

From Cardiovascular Research ${ }^{\mathrm{a}}$ and the Cancer Research Program, ${ }^{\mathrm{b}}$ Research Institute, The Hospital for Sick Children, Toronto, Ontario, Canada.

Read at the Eighty-sixth Annual Meeting of The American Association for Thoracic Surgery, Philadelphia, Pa, April 29-May 3, 2006.

Received for publication April 28, 2006; revisions received June 29, 2006; accepted for publication Aug 3, 2006.

Address for reprints: J. G. Coles, MD, Division of Cardiovascular Surgery, Hospital for Sick Children, 555 University Ave, Toronto, ON M5G 1X8, Canada (E-mail: john.coles@sickkids.ca).

*These authors contributed equally to this manuscript.

J Thorac Cardiovasc Surg 2006;132:1272-9

$0022-5223 / \$ 32.00$

Copyright $(\odot) 2006$ by The American Association for Thoracic Surgery

doi:10.1016/j.jtcvs.2006.08.028
Objective: Recent evidence suggests that the adult heart contains stem cells that are capable of self-renewal as well as multilineage differentiation. However, their inherent capacity for self-renewal is limiting to cell replacement applications. Integrin-linked kinase is a multifunctional protein kinase that activates Wnt target genes implicated in the symmetric replication of embryonic stem cells.

Methods: Primary cultures derived from human fetal cardiac tissue (19-22 weeks' gestation) were grown in serum-free media and evaluated for the presence of cardiac progenitor cells. The effect of integrin-linked kinase was ascertained by adenoviral overexpression.

Results: Cultures infected with wild-type integrin-linked kinase yielded a significant $(P=.001)$, approximately 5 -fold increase in both the absolute number and the frequency of c-Kit-positive, myosin-negative cells. Cardiospheres, comprised on morphologically homogeneous, anchorage-independent cells, were reproducibly present at days 7 to 10 and formed derivative cardiospheres in multiple passages. Integrin-linked kinase infection of primary cardiac cell cultures resulted in a greater number of primary spheres at each cell density tested, compared with untreated and virus controls $(P=.001)$. Secondary spheres transferred to differentiation medium and 5-aza-deoxycytodine $(10 \mu \mathrm{mol} / \mathrm{L})$ generated cells exhibiting biochemical evidence of differentiation into cardiomyocytes, smooth muscle cells, and endothelial cells.

Conclusions: This study demonstrates that self-renewing cardiospheres generated from human fetal cardiac cells are composed of cells exhibiting the properties of stem cells, including the capacity for self-renewal and multilineage differentiation. Our results suggest that integrin-linked kinase promotes stem cell amplification and can be applied therapeutically to overcome a major limitation in the field of cardiac regenerative medicine.

$\mathrm{R}$ ecent studies have challenged the traditional thinking that the adult mammalian heart lacks inherent regenerative capacity. Cardiac stem cells derived from bone marrow or niches within the heart have been identified and shown to participate in the regeneration of myocardium in vivo. ${ }^{1-3}$ Tissue-resident cardiac progenitor cells expressing various stem cell markers such as Sca-1, MDR-1, and c-Kit, exhibit the hallmarks of adult stem cells: self-renewal, clonogenicity, and multilineage differentiation. However, the population of progenitor cells in the heart is very low, and the inability to expand this population of cells in vitro or in vivo represents a major barrier to therapeutic stem cell applications.

Integrin-linked kinase (ILK) is a multifunctional protein kinase that coordinates signal transduction by integrins and growth factor receptors and serves as a nodal regulator of protein kinase cascades important to cell proliferation, differentiation, and apoptosis. ${ }^{4,5}$ ILK functions as the effector of phosphoinositide-3'-OH kinase 


$$
\begin{aligned}
& \text { Abbreviations and Acronyms } \\
& \begin{aligned}
\text { Ad.C } & =\text { virus control } \\
\text { bFGF } & =\text { basic fibroblast growth factor } \\
\text { CS } & =\text { cardiosphere } \\
\text { DAPI } & =4,6 \text {-diamino-2-phenylindole } \\
\text { EGF } & =\text { endothelial growth factor } \\
\text { FBS } & =\text { fetal bovine serum } \\
\text { GFP } & =\text { green fluorescent protein } \\
\text { GSK-3 } 3 & =\text { glycogen synthase kinase- } 3 \beta \\
\text { ILK } & =\text { integrin-linked kinase } \\
\text { IMDM } & =\text { Iscove modified Dulbecco medium }
\end{aligned}
\end{aligned}
$$

signaling, following distinct signal inputs from integrins and growth factor receptor tyrosine kinases. ${ }^{6,7}$ ILK also inhibits glycogen synthase kinase-3ß (GSK-3ß), ${ }^{5,8}$ which leads to the nuclear accumulation of $\beta$-catenin. This, in turn, leads to the activation of Wnt target genes implicated in the maintenance and symmetric replication of embryonic stem cells, as well as their more tissue- and lineage-restricted progeny. The canonical $\mathrm{Wnt} / \beta$-catenin signaling pathway has been shown to be important in both embryonic and adult stem cell maintenance and self-renewal in hematopoetic, gastrointestinal, and neural tissues, ${ }^{9-12}$ although this pathway has not been studied in cardiac stem cells.

Here we show that the overexpression of ILK in human fetal cardiac tissue in vitro increases the population of cardiac stem cells, which exhibit self-renewal and multilineage differentiation. Our results suggest that gain-of-function of a gene that promotes stem cell amplification can be applied therapeutically to help overcome a major limitation in the field of regenerative medicine.

\section{Methods \\ Isolation and Cell Culture}

Human fetal hearts were harvested during elective pregnancy termination at the gestational ages of 19 to 22 weeks, in accordance with the guidelines of the Institutional Human Research Ethics Board of The Hospital for Sick Children and after obtaining maternal consent.

The hearts were minced and washed with phosphate-buffered saline. Cell isolation was accomplished with $0.2 \%$ trypsin and 1.0 $\mathrm{mg} / \mathrm{mL}$ type II collagenase in a $0.02 \%$ glucose phosphate-buffered saline solution at $37^{\circ} \mathrm{C}$. After dissection, cells were incubated on precoated plastic culture dishes (Starstedt, Inc, Newton, NC) for 2 hours at $37^{\circ} \mathrm{C}$ to remove fibroblasts, with Iscove modified Dulbecco medium (IMDM; Gibco; Invitrogen Corporation, Carlsbad, Calif) containing penicillin and streptomycin and supplemented with $10 \%$ fetal bovine serum (FBS; Gibco). After incubation, the supernatant was removed, added to precoated culture dishes (Sarstedt), and placed in a 5\% carbon dioxide incubator at $37^{\circ} \mathrm{C}$.

\section{Gene Transfer}

Cells were cultured to $60 \%$ to $70 \%$ confluency in preparation for adenovirally mediated infection of ILK constructs incorpo- rating green fluorescent protein (GFP), as previously described. ${ }^{13}$ Replication-deficient serotype 5 adenovirus encoding either the human wild-type ILK gene (Ad.ILK-GFP) or empty virus constructs incorporating a GFP tag (Ad.C), previously shown to modulate ILK expression and activity in L6 myoblasts, ${ }^{14}$ were used for the infection of cells. Cells were infected at $37^{\circ} \mathrm{C}$ at multiplicity of infection of 1.5 in IMDM with 10\% FBS for 24 hours. Effective gene transfer was confirmed by more than $80 \%$ of GFP positivity.

\section{Western Blot Analysis}

Western blot analysis was performed to confirm the transduction of Ad.ILK in cardiac cell cultures. The cells were washed with phosphate-buffered saline and harvested by scraping in lysis buffer. After measurement of protein expression, analyses were performed with polyclonal anti-ILK antibody (Cell Signaling Technology, Inc, Danvers, Mass). Proteins were visualized with an enhanced chemiluminescence detection reagent (Amersham Pharmacia Biotech, Piscataway, NJ) and quantified by densitometry.

\section{Immunocytochemistry and Quantitative Analysis of c-Kit-positive Cells}

Cells were fixed with methanol at $-20^{\circ} \mathrm{C}$ for 20 minutes. Cells were then reacted with c-Kit antibody (diluted 1:20; Assay Designs, Inc, Ann Arbor, Mich), human monoclonal the following: anti-CD34 (Cymbus Biotechnology, Ltd, Eastleigh, Southampton, United Kingdom), human monoclonal anti- $\alpha$-smooth muscle actin (1:100; Santa Cruz Biotechnology, Inc, Santa Cruz, Calif), human polyclonal anti-von Willebrand factor (1:200), myosin monoclonal antibody (MF20 diluted 1:10), or monoclonal anti- $\alpha$ actinin (1:200) from Sigma Chemical Company (St Louis, Mo). Nuclei were stained with 4,6-diamino-2-phenylindole (DAPI). All slides were analyzed at $20 \times$ magnification with a Leica fluorescent microscope with a coupled camera (Leica Microsystems $\mathrm{GmbH}$, Wetzlar, Germany). All analysis was done with OpenLab 4.0.2 software (Agilent Technologies, Scientific Software Inc, Palo Alto, Calif). More than 10 fields were randomly chosen and photographed, and the total cell number $(\sim 5000 /$ dish $)$ was counted manually in a fashion blinded to viral status.

\section{Generation of Primary and Secondary Spheres}

Cell viability was confirmed with trypan blue staining before plating at densities from 10 cells $/ \mu \mathrm{L}$ to 1 cell $/ \mu \mathrm{L}$ in 24 -well plates. The culture medium was composed of Dulbecco modified Eagle medium/F-12 (1:1) including Hepes buffer ( $5 \mathrm{mmol} / \mathrm{L})$, glucose $(0.6 \%)$, sodium bicarbonate $(3 \mathrm{mmol} / \mathrm{L})$, glutamine $(2 \mathrm{mmol} / \mathrm{L})$, insulin $(25 \mu \mathrm{g} / \mathrm{mL})$, transferrin $(100 \mu \mathrm{g} / \mathrm{mL})$, progesterone $(20$ $\mathrm{nmol} / \mathrm{L})$, putrescine $(60 \mu \mathrm{mol} / \mathrm{L})$, sodium selenite $(30 \mathrm{nmol} / \mathrm{L})$, human recombinant endothelial growth factor (EGF; $20 \mathrm{ng} / \mathrm{mL}$ ), and basic fibroblast growth factor (bFGF; $20 \mathrm{ng} / \mathrm{mL}$ ). The number of primary spheres generated in each well was assessed 14 days after plating. Primary spheres were dissociated into single cells consisting of approximately 200 to 500 cells, which were placed in 96-well plates. The number of secondary spheres was assessed 14 days after replating dissociated cells.

\section{Differentiation Assay}

Secondary spheres were transferred to differentiation medium, which was composed of IMDM containing 10\% FBS and 10 

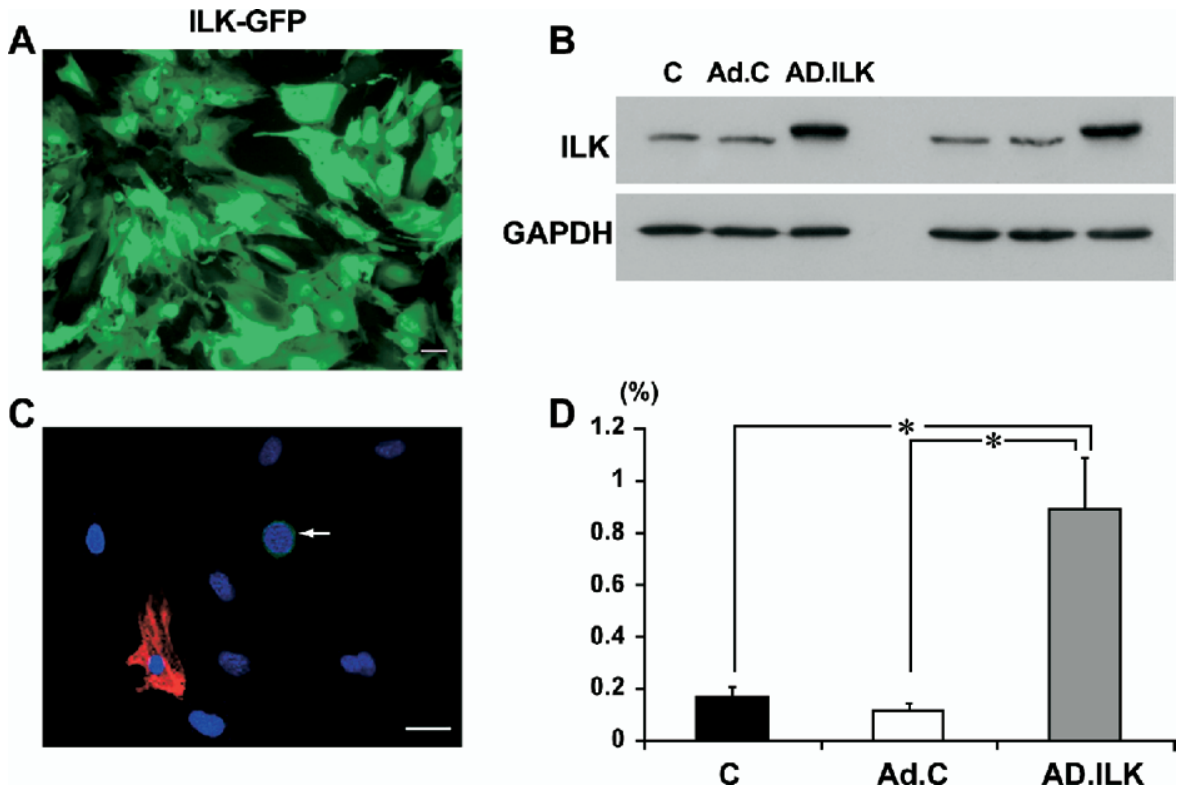

Figure 1. Adenovirus encoding either the human wild-type human gene linked to GFP (AD.ILK) or empty virus (Ad.C) was used to infect human fetal cardiomyocytes cultured in IMDM supplemented with $10 \%$ FBS. A, Effective gene transfer was confirmed by more than $\mathbf{8 0} \%$ GFP positivity. B, ILK infection increased ILK protein expression approximately 3-fold; the Western blots shown are representative of 5 independent experiments. GAPDH, Glyceraldehyde-3-phosphate dehydrogenase. C, Cardiac cell cultures labeled with c-Kit (green) and cardiac myosin MF2O (red). Arrow indicates c-Kit-positive cell. Nuclei were stained with DAPI (blue). Scale bar $=10 \mathrm{~mm}$. D, Cultures infected with ILK yielded a significant $\left({ }^{*} P=.001\right)$ approximately 5 -fold increase in both the absolute number and the frequency of c-Kit-positive cells, which reached approximately one cell in 250 . Analysis is based on 5 independent experiments. Error bars indicate standard error of the mean. GFP, green fluorescent protein; IMDM, Iscove modified Dulbecco medium; FBS, fetal bovine serum; ILK, integrin-linked kinase.

$\mu \mathrm{mol} / \mathrm{L}$ 5-aza-2'-deoxycytodine (5azaD). Cells migrating out from the spheres were analyzed by immunocytochemistry on day 14 . Cells were fixed and characterized by staining with the following markers: $\alpha$-cardiac actinin antibody, MF20, directed to $\alpha$-cardiac myosin heavy chain, von Willebrand factor antibody (diluted 1:200; Dako, Glostrup, Denmark), or $\alpha$-smooth muscle actin antibody (diluted 1:100; Santa Cruz).

\section{Results}

ILK Increases the Frequency of c-Kit-positive Cells To determine whether the overexpression of ILK increases the stem cell number in the human heart, we acquired fetal hearts of gestational ages 19 to 22 weeks during elective pregnancy termination, and the hearts were enzymatically dissociated into single cell suspension. The cells were incubated on precoated plastic culture dishes for 2 hours at $37^{\circ} \mathrm{C}$ to remove fibroblasts, which were shown to be devoid of c-Kit-positive cells. At 2 to 3 days after isolation and at $60 \%$ to $70 \%$ confluency, cells were infected with replication defective adenovirus containing wild-type (Ad.ILK) or virus control (Ad.C). Effective gene transfer was confirmed by more than $80 \%$ GFP positivity (Figure 1, $A$ ) and by approximately 3 -fold increase in ILK protein expression (Figure 1,B) in cell cultures. Isolated c-Kit-positive cells imaged by fluorescence microscopy were typically negative for the cardiac myosin markers $\alpha$-cardiac actinin (Figure 1, C), MF20, and the hematopoetic stem cell marker CD34. Cultures infected with wild-type ILK yielded a significant $(P=$
.001), approximately 5-fold increase in both the absolute number and the frequency of c-Kit-positive cells, which reached approximately one cell in 250 (Figure 1, D).

\section{Human Fetal Cardiac Cells Generate Cardiospheres In Vitro}

To determine whether primary human fetal cardiac cells generate cardiospheres (CSs) in vitro, cells were infected with Ad.ILK or Ad.C and plated in serum-free medium supplemented with $20 \mathrm{ng} / \mathrm{mL}$ each of EGF and bFGF at clonal density of a single cell per well in 24-well plates. Primary CSs, comprised on morphologically homogeneous cells, were reproducibly present at days 7 to 10 (Figure 2, upper panel). CSs were noted to be uniformly free-floating, presumably reflecting anchorage-independence, in distinction to cardiac myocytes, which became rapidly adherent to the culture plate surface. Cells from dissociated primary CSs were plated at a density corresponding to one sphere ( 200-400 cells) per well. Secondary CSs, which were morphologically indistinguishable from primary CSs, were evident in approximately $60 \%$ of wells at day 14 (Figure 2, lower panel). CSs were shown to be composed of cells expressing the c-Kit-positive surface receptor (Figure 3). CSs contained cells that invariably stained for c-Kit, often costaining with cardiac myosin markers $\alpha$-cardiac actinin or MF20; in others the majority of cells stained exclusively for 


\section{Primary Spheres}
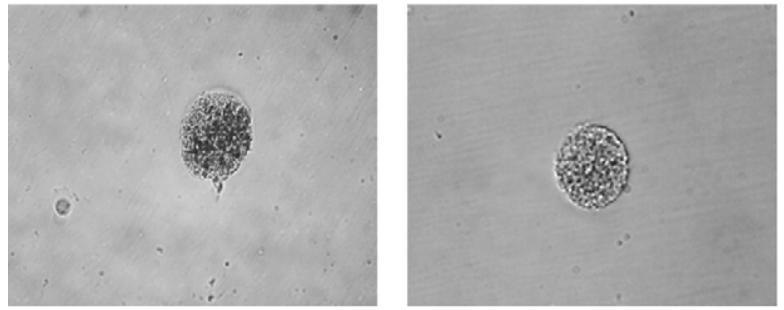

Secondary Spheres

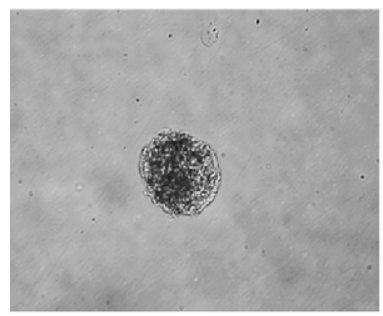

Control

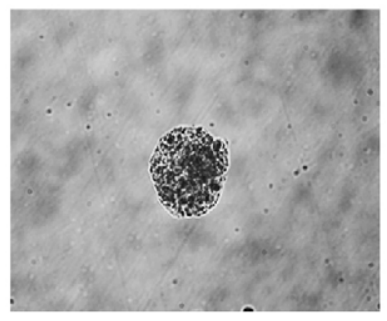

Ad.C
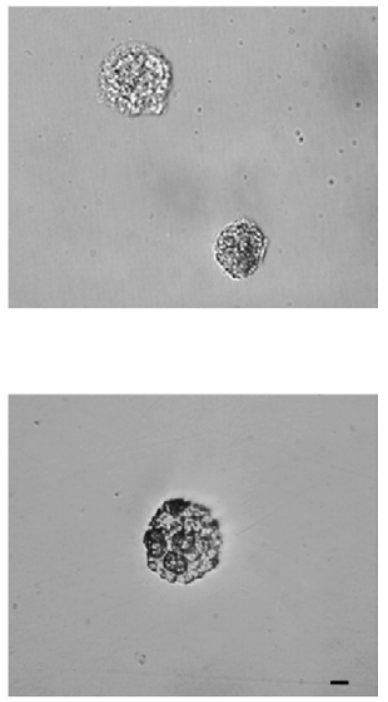

Ad.ILK
Figure 2. Primary cardiospheres (CSs) were generated from human fetal cardiomyocytes grown in serum-free media supplemented with bFGF and EGF (Methods) and imaged with natural light phase microscopy. Dissociated primary CSs composed of homogeneous phase-bright cells placed in wells containing the same media gave rise to secondary CSs in approximately $60 \%$ of wells. bFGF, basic fibroblast growth factor; $E G F$, endothelial growth factor.
c-Kit with only occasional cells at the periphery of the spheres staining for the cardiac marker $\alpha$-actinin (arrowhead).

\section{ILK Overexpression Increases the Rate of CS Formation}

ILK infection of primary cardiac cell cultures resulted in a greater number of primary spheres at each cell density tested, compared with untreated and virus controls (Figure 4, A). Among CSs generated from ILK-infected cultures, approximately $80 \%$ stained homogeneously for ILK-GFP; approximately $20 \%$ exhibited no evidence of GFP staining; and no spheres were observed that were mosaic for GFP, suggesting origin from a single cell rather than cellular aggregation.

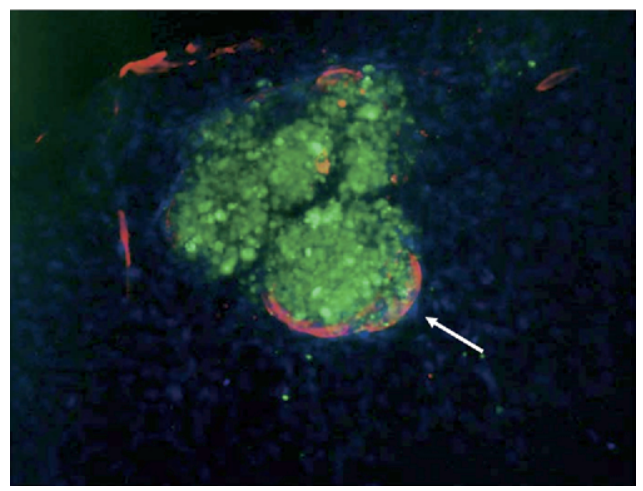

Figure 3. CSs were composed of cells expressing the c-Kitpositive surface receptor. Occasional cells at the periphery of the spheres stain for the cardiac marker $\alpha$-actinin (arrow), suggesting a radial gradient in the differentiation of constituent cells. CSs, cardiospheres.
The frequency of sphere-initiating cells, as measured by the ratio of sphere number/total cell number, was significantly greater in ILK-overexpressing cultures (Figure 4, B). The frequency of secondary or tertiary spheres generated from primary spheres composed of Ad.ILK, Ad.C, or uninfected cells was highly similar ( $\sim 60 \%$ of wells), indicating that while ILK gain-of-function increases the formation of primary spheres, it does not alter their inherent capacity for subsequent self-renewal.

Cardiac stem cells are multipotent and have the capacity to differentiate into smooth muscle, cardiac, and endothelial cells. ${ }^{1,15,16}$ Secondary spheres were transferred to differentiation medium consisting of IMDM with $10 \%$ FBS and the methyltransferase inhibitor, 5azaD (10 $\mu \mathrm{mol} / \mathrm{L})$. Within 4 to 5 days, spheres became attached to the plate and individual cells migrated from spheres, which exhibited biochemical evidence of differentiation into cardiomyocytes, smooth muscle cells, and endothelial cells (Figure 5). The profile of differentiated cells among ILK-overexpressing and control cells was highly similar (Figure 5, lower left panel), indicating that ILK-induced clonal proliferation of cardiac stem cells does not impair their capacity for multilineage differentiation.

\section{Discussion}

The heart contains several classes of primitive cells with the capacity for regeneration based on differences in surface antigen expression reflecting variable degrees of differentiation, as well as by variations in the isolation protocols that affect antigen expression. ${ }^{17} \mathrm{We}$ identified cells derived from primary cardiac tissue, which robustly stained for c-Kit anti- 
A Primary Sphere Formation

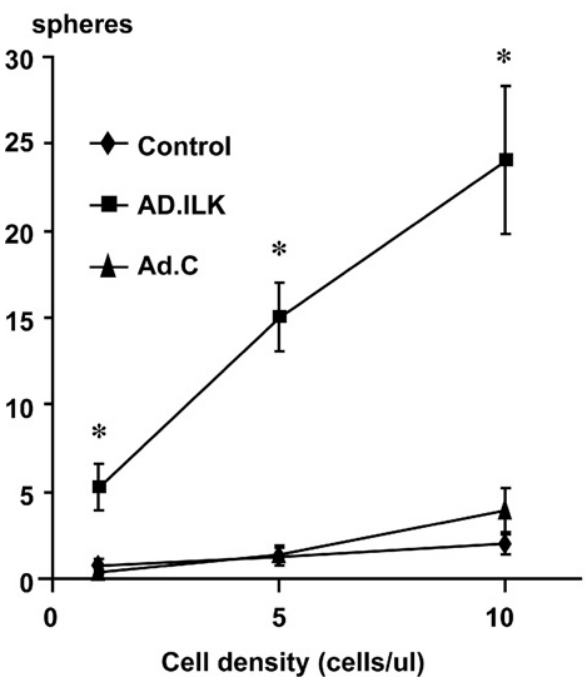

B Sphere Initiating Ratio

(\%)

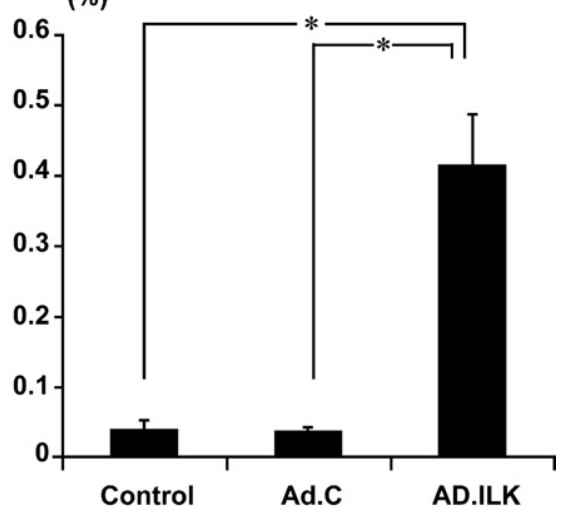

Figure 4. A, CSs were observed in human fetal cardiac cell cultures. Cardiac cells were infected with adenoviral ILK (Ad.ILK) or empty viral vector (Ad.C) (at $10 \mathrm{pfu} / \mathrm{mL}$ ) or left untreated (Control). ILK infection resulted in significant $\left({ }^{*} P<.01\right)$ increases in the absolute number and frequency of CSs at all plating densities tested. B, The number of primary sphere-initiating cells ratio was significantly higher in ILK-infected cells $\left({ }^{*} P=.002\right)$. Whereas $0.41 \% \pm 0.073 \%$ of ILK-infected cells generated spheres, only $0.037 \% \pm 0.014 \%$ of control cells and $0.035 \% \pm 0.006 \%$ of virus-only cells generated spheres. Analysis is based on 6 independent experiments. Error bars represent standard error of the mean. CSs, cardiospheres; ILK, integrin-linked kinase. gen but not markers of cardiac differentiation. These cells were enriched in self-aggregating, anchorage-independent spheres, which were shown to be clonogenic in derivative passage. Further, the cells comprising the spheres exhibited the capacity to generate multiple cardiac cell lineages in vitro, confirming their identity as cardiac progenitor cells.

Several studies in the human heart have shown that c-Kit represents the most conserved marker for a progenitor cell

\section{Cardiomyogenesis in Secondary Cardiospheres}

A
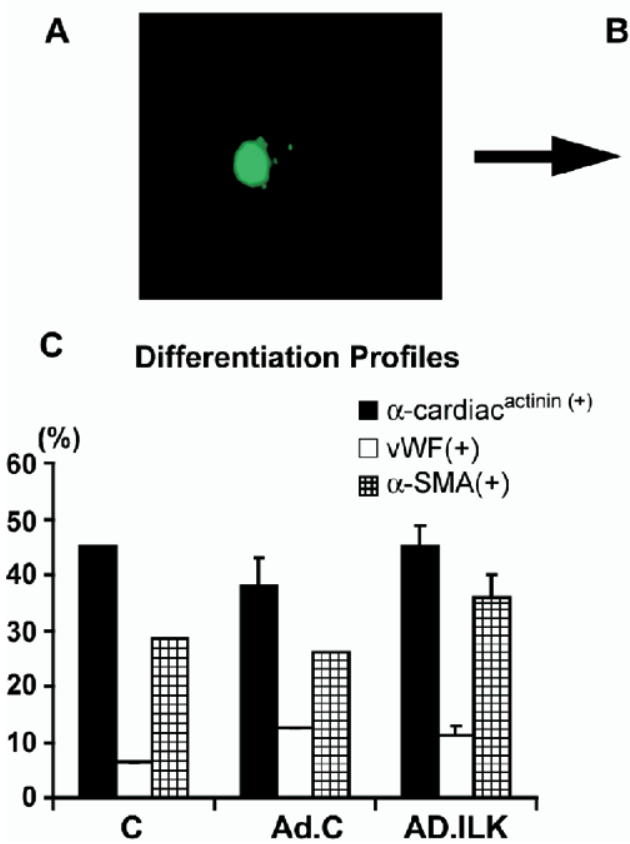

B

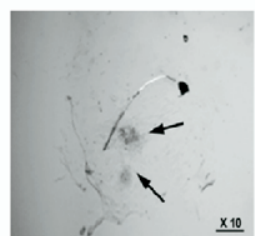

Natural light

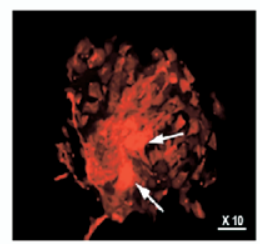

Alpha-cardiac actinin

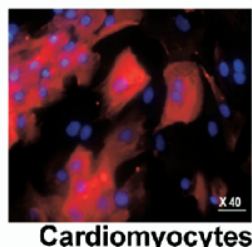

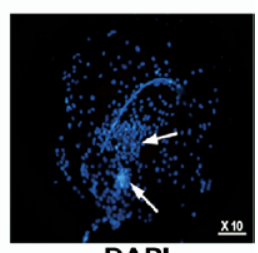

DAPI

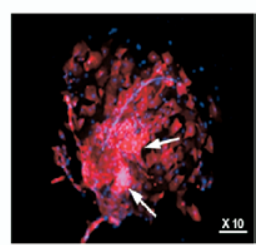

Merged

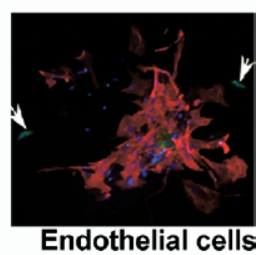

Figure 5. A, Secondary CSs, derived from cells isolated from a dissociated primary CS, shown in upper left panel, contains ILK-infected GFP-positive cells. CSs were placed in differentiating medium (IMDM $+10 \%$ FBS) containing the 5-methyltransferase inhibitor, 5azaD (10 $\mu \mathrm{mol} / \mathrm{L})$ for 14 days. B, Arrows indicate CS-containing cells marked by DAPI staining, which are also positive for the cardiomyocyte-specific marker, $\alpha$-cardiac actinin. Lower panel (left) shows a higher-power view of cells migrating outward from CSs, $45 \%$ to $50 \%$ of which are cardiomyocytes. Lower panel (right) shows that approximately $10 \%$ of CS-derived cells stain positively (green) for von Willebrand factor (vWF), indicative of endothelial cell lineage. Thirty-five percent to $40 \%$ of cells stained positively for $\alpha$-smooth muscle actin (SMA) (not shown). C. The differentiation profiles were similar among ILK-infected (Ad.ILK), empty virus $(A D . C)$, and control CSs. This result indicates the feasibility of manipulating the phenotypic outcome of cardiac progenitor cells, even among ILK-transformed cells. CSs, cardiospheres; ILK, integrin-linked kinase; GFP, green fluorescent protein; IMDM, Iscove modified Pulbecco medium; DAPI, 4,6-diamino-2-phenylindole. 
population, with the properties of self-renewal, clonogenicity, and multipotency. ${ }^{1,16-18}$ The proto-oncogene c-Kit encodes a transmembrane tyrosine kinase receptor, and the ligand for $\mathrm{c}-\mathrm{Kit}$ has been identified to be stem cell factor. ${ }^{19}$ The capacity of c-Kit-positive clonogenic cells to generate cardiac cell lineages in vitro and to regenerate myocardium after experimental myocardial infarction ${ }^{1}$ and ischemiareperfusion in vivo is superior to that of Sca-1-positive or MDR-1-like cells. ${ }^{20}$ Accordingly, we relied on c-Kit expression to mark a cardiac progenitor cell population in human fetal myocardium, in order to determine the influence of ILK gain-of-function on cardiac stem cell proliferation. Although we did not perform comprehensive antigen profiling on cardiac progenitor cells isolated via our protocol, we did not identify cells that immunostained for islet-1, which is a transcription factor associated with commitment to the cardiomyocyte lineage previously described in the newborn human heart, ${ }^{21}$ nor did we identify cells that expressed the hematopoetic stem cell marker CD34. The latter result suggests that CSs were derived from a cardiac resident, rather than from a bone marrow-mobilized, cellular population. $^{22}$

We postulated that human fetal cardiac tissue would be enriched for stem cells, which are important during cardiogenesis. ${ }^{21}$ Inasmuch as it has been reported that cardiac c-Kit-positive cells can differentiate into the various cardiac lineages, including cardiomyocytes, smooth muscle, and endothelial cells, ${ }^{3} \mathrm{c}$-Kit antibody was used as a marker for cardiac stem cells. We took advantage of the tendency of cardiac cells to form macroscopic CSs when grown on nonadhesive substrata in the presence of growth factor supplementation. Using the capacity to form CSs as a readout for stem cell frequency, we tested whether adenoviral ILK overexpression would cause proliferation of CS-forming cells with self-renewal, clonogenic, and multidifferentiation properties.

c-Kit-positive cells occur either as isolated cells or in the form of macroscopic CSs, analogous to neurospheres containing c-Kit-positive, multipotent neural stem cells. ${ }^{23,24}$ CSs have been previously characterized as lineage-negative, c-Kit-positive, morphologically homogeneous cells, having the capacity for self-renewal as well as differentiation into functional cardiac myocytes, and to participate in the regeneration of functional myocardium in vivo. ${ }^{15}$ Immunostaining revealed that constituent cells contained in spheres, although invariably c-Kit-positive, sometimes possessed sarcomeric structures as assessed by antibody labeling directed to cardiac markers such as MF20 and $\alpha$-cardiac actinin. This finding raises the possibility that CSs represent clusters of terminally differentiated cardiac myocytes undergoing cellular replication by mitoses, rather than bona fide cardiac progenitor cells. However, our findings argue that the c-Kit-positive, $\alpha$-cardiac actinin-positive cells in

\section{Canonical Wnt Pathway}
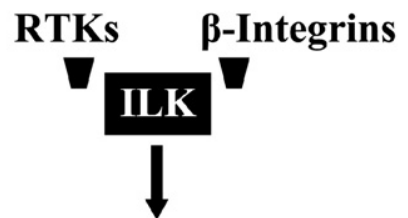

GSK-3及

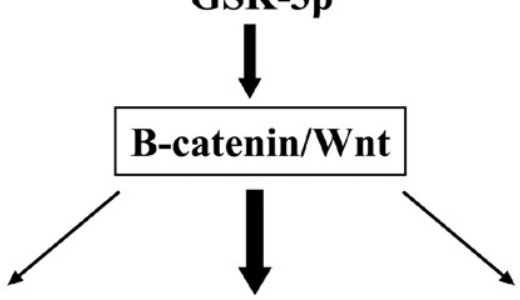

Survival/

Development

Stem Cell Renewal Oncogenesis

Figure 6. ILK is a multifunctional protein kinase that coordinates signal transduction by integrins and growth factor receptor tyrosine kinases (RTKs). ILK negatively modulates GSK-3 $\beta$ activity, promotes nuclear activation of $\alpha$-catenin, and is a candidate kinase activator of canonical Wnt pathway signaling. ILK promotes anchorage-independent survival and cell cycle transit as a result of cyclin D activation, providing a potential molecular basis for both oncogenesis and stem cell self-renewal. ILK,

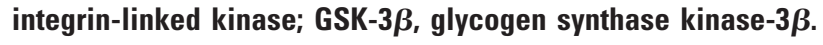

CSs represent the progeny by asynchronous cellular division of an undifferentiated c-Kit-positive progenitor cell. This interpretation holds that the variable expression of cardiomyocyte markers present in the spheres reflects variable degrees of lineage commitment among constitutent cells and their progeny. It is supported by our results, which demonstrate the capacity of CSs to exhibit multilineage differentiation into smooth muscle, cardiac, and endothelial cells in response to $5 \mathrm{azaD}$ exposure, as described previously. ${ }^{15}$

The evolutionarily conserved canonical Wnt pathway has been implicated in both human and mouse embryonic stem cell self-renewal competence. ${ }^{11}$ The $\mathrm{Wnt} / \beta$-catenin signaling pathway is required for maintaining proliferation of neuronal progenitors ${ }^{12}$ and for hematopoietic stem cell homeostasis. ILK negatively modulates of GSK-3 $\beta$ activity, promotes nuclear activation of $\beta$-catenin, ${ }^{12,25,26}$ and is a candidate kinase activator of Wnt pathway signaling ${ }^{5}$ (Figure 6). ILK overexpression or constitutive activation promotes cell cycle transit through a signaling pathway comprising the Wnt components GSK-3ß and B-catenin, leading to increased expression of cyclin $\mathrm{D} 1^{27}$ and providing a molecular basis for the inherent proliferation (selfrenewal) property of stem cells. Moreover, ILK promotes anchorage-independent survival, which appears to be a ge- 
neric and poorly understood feature of stem cells, including c-Kit-containing CSs isolated from adult rat $^{1}$ and human hearts. ${ }^{15}$

This study demonstrates that self-renewing CSs generated from human fetal cardiac cells are composed of cells exhibiting the properties of stem cells, including the capacity for self-renewal and multilineage differentiation. This result has also been reported for putative cardiac stem cells in cardiac cells isolated from adult rodent, ${ }^{1}$ murine,,${ }^{16}$ and human atrial biopsies. ${ }^{15}$ Overexpression of ILK resulted in an approximately 10-fold increase in the frequency of sphere-initiating cells. Importantly, ILK-transformed stem cells are shown to be equally susceptible to cardiac differentiation, even while exhibiting an increased capacity for proliferation and CS formation.

ILK is positioned to transduce distinct signal inputs from integrins and growth factor receptor tyrosine kinases, ${ }^{28,29}$ is an activator of the Wnt pathway, ${ }^{6}$ and promotes anchorageindependent cellular proliferation, ${ }^{5,7}$ thus providing a putative molecular basis for the observed amplification effect on the cardiac stem cell population. An ILK-dependent increase in cardiac stem cell frequency is consistent with the finding that vascular endothelial growth factor has been shown to positively regulate hematopoetic stem cell survival, ${ }^{30}$ since ILK positively regulates vascular endothelial growth factor expression through a hypoxia-inducible factor- $1 \alpha$-dependent pathway. ${ }^{4}$ The fact that ILK effect was evident even under conditions of growth factor supplementation supports the rationale of exploiting upregulation of the ILK signaling pathway as a novel strategy to promote therapeutically useful expansion of a target stem cell population.

In summary, these experiments identify ILK as a novel molecular target impinging on cardiac stem cell amplification. These findings have important therapeutic implications for potential ex vivo manipulation of cardiac stem cells in conjunction with cellular transplantation, and they also anticipate future strategies designed to exploit the recruitment of endogenous cardiac progenitor cells.

\section{Limitations}

More definitive characterization of the phenotype and state of commitment of cells comprising CSs toward the cardiomyocyte lineage, and the effect of ILK gain-of-function on these cells, will require further profiling with cardiac stem cell markers such as islet- $1,{ }^{21}$ as well as earlier ( $\left.\mathrm{Nkx} 2.5\right)$ cardiac genes, in addition to more mature cardiac genes (Mef2c, $\alpha$-actinin) surveyed in this study. Methods incorporating fluorescent tags linked to promoter regions of early cardiac genes would help to further confirm the differentiation potential of CSs and the effects of ILK gene transfer on the capacity for symmetric versus asymmetric cellular division generating terminally differentiated cardiac cells.
Further, the specific ILK-regulated signaling pathways that govern self-renewal and differentiation in this unique stem cell population await clarification.

\section{References}

1. Beltrami AP, Urbanek K, Leri A, Kajstura J, Nadal-Ginard B, Anversa P. Adult cardiac stem cells are multipotent and support myocardial regeneration. Cell. 2003;114:763-76.

2. Oh H, Schneider MD. Cardiac muscle plasticity in adult and embryo by heart-derived progenitor cells. Ann N Y Acad Sci. 2004;1015:182-9.

3. Anversa P, Nadal-Ginard B. Myocyte renewal and ventricular remodelling. Nature. 2002;415:240-3.

4. Hannigan GE, Leung-Hagesteijn C, Fitz-Gibbon L, Coppolino MG, Radeva G, Filmus J, et al. Regulation of cell adhesion and anchoragedependent growth by a new beta 1-integrin-linked protein kinase. Nature. 1996;379:91-6.

5. Hannigan G, Troussard AA, Dedhar S. Integrin-linked kinase: a cancer therapeutic target unique among its ILK. Nat Rev Cancer. 2005;5:51-63.

6. Troussard AA, Dedhar S. Conditional knock-out of integrin-linked kinase demonstrates an essential role in protein kinase B/Akt activation. J Biol Chem. 2003;278:22374-8.

7. Leung-Hagesteijn C, Mahendra A, Naruszewicz I, Hannigan GE. Modulation of integrin signal transduction by ILKAP, a protein phosphatase $2 \mathrm{C}$ associating with the integrin-linked kinase, ILK1. EMBO J. 2001;20:2160-70.

8. Choi JH, Hur J, Yoon CH, Kim JH, Lee CS, Young SW, et al. Augmentation of therapeutic angiogenesis using genetically modified human endothelial progenitor cells with altered glycogen synthase kinase-3\{beta\} activity. J Biol Chem. 2004;279:49430-8.

9. Eckfeldt CE, Mendenhall EM, Verfaillie CM. The molecular repertoire of the "Almighty" stem cell. Nat Rev Mol Cell Biol. 2005;6: 726-37.

10. Reya T, Clevers H. Wnt signalling in stem cells and cancer. Nature. 2005;434:843-50.

11. Liu BY, McDermott SP, Khwaja SS, Alexander CM. The transforming activity of Wnt effectors correlates with their ability to induce the accumulation of mammary progenitor cells. Proc Natl Acad Sci U S A. 2004;101:4158-63

12. Zechner D, Fujita Y, Hulsken J, Muller T, Walther I, Taketo MM, et al. 3 -Catenin signals regulate cell growth and the balance between progenitor cell expansion and differentiation in the nervous system. Dev Biol. 2003;258:406-18.

13. Coles JG, Takahashi M, Dai X, Boscarino C, Hannigan G. Cardioprotective stress response in the human fetal heart. $J$ Thorac Cardiovasc Surg. 2005;129:112-36.

14. Miller MG, Hannigan GE. Integrin-linked kinase is a positive mediator of L6 myoblast differentiation. Biochem Biophys Res Commun. 2003 310:796-803.

15. Messina E, De Angelis L, Frati G, Morrone S, Chimenti S, Fiordaliso $\mathrm{F}$, et al. Isolation and expansion of adult cardiac stem cells from human and murine heart. Circ Res. 2004;95:911-21.

16. Matsuura K, Komuro I. Adult cardiac Sca-1-positive cells differentiate into beating cardiomyocytes. J Biol Chem. 2004;279:11384-91.

17. Anversa P, Kajstua J, Leri A, Bolli R. Life and death of cardiac stem cells: a paradigm shift in cardiac biology. Circulation. 2006; 113:1451-63.

18. Urbanek K, Rota M, Cascapera S, Bearzi C, Nascimbene A, DeAngelis A, et al. Cardiac stem cells possess growth factor-receptor systems that following activation regenerate the infarcted myocardium improving ventricular function and long-term survival. Circ Res. 2005;97: 663-73.

19. Yamataka A, Ohshiro K, Kobayashi H, Lane GJ, Yamataka T, Fujiwara T, et al. Abnormal distribution of intestinal pacemaker (C-KITpositive) cells in an infant with chronic idiopathic intestinal pseudoobstruction. J Pediatr Surg. 1998;33:859-62.

20. Linke A, Muller P, Nurzynska D, Casars C, Torella D, Nascimbene A, et al. Stem cells in the dog heart are self-renewing, clonogenic, and 
multipotent and regenerate infarcted myocardium, improving cardiac function. Proc Natl Acad Sci U S A. 2005;102:8966-71.

21. Laugwitz KL, Moretti A, Lam J, Gruber P, Chen Y, Woodard S, et al. Postnatal is $11+$ cardioblasts enter fully differentiated cardiomyocyte lineages. Nature. 2005;433:647-53.

22. Araki H, Mahmud N, Milhem M, Nunez R, Xu M, Beam CA, et al. Expansion of human umbilical cord blood SCID-repopulating cells using chromatin-modifying agents. Exp Hematol. 2006;34:140-9.

23. Milosevic J, Storch A, Schwarz J. Cyropreservation does not affect proliferation and multipotency of murine neural precursor cells. Stem Cells. 2005;23:681-8.

24. Lee A, Kessler JD, Read T-A, Kaiser C, Coreil D, Huttner WB, et al. Isolation of neural stem cells from the postnatal cerebellum. Nat Neurosci. 2005;8:723-9.

25. Novak A, Dedhar S. Signaling through beta-catenin and Lef/Tcf. Cell Mol Life Sci. 1999;56:523-37.

26. Tan C, Dedhar S. Inhibition of integrin linked kinase (ILK) suppresses beta-catenin-Lef/Tcf-dependent transcription and expression of the E-cadherin repressor, snail, in APC-/- human colon carcinoma cells. Oncogene. 2001;20:133-40.

27. Kumar AS, Naruszewicz I, Wang P, Leung-Hagesteijn C, Hannigan GE. ILKAP regulates ILK signaling and inhibits anchorage-independent growth. Oncogene. 2004;23:3454-61.

28. Troussard AA, Tan C, Yoganathan N, Dedhar S. Cell-extracellular matrix interactions stimulate the AP-1 transcription factor in an integrin-linked kinase- and glycogen synthase kinase 3-dependent manner. Mol Cell Biol. 1999;19:7420-7.

29. Persad S, Attwell S, Gray V, Delcommenne M, Troussard A, Sanghera $\mathrm{J}$, et al. Inhibition of integrin-linked kinase (ILK) suppresses activation of protein kinase B/Akt and induces cell cycle arrest and apoptosis of PTEN-mutant prostate cancer cells. Proc Natl Acad Sci U SA. 2000; 97:3207-12.

30. Gerber HP, Malik AK, Solar GP, Sherman D, Liang XH, Meng G, et al. VEGF regulates haematopoietic stem cell survival by an internal autocrine loop mechanism. Nature. 2002;417:954-8.

\section{Discussion}

Dr Frank W. Sellke (Boston, Mass). This is a very nice in vitro study of the effects of overexpression of ILK on cardiac stem cell growth.

I have a couple questions. Was the purpose of this study just to increase expansion of the stem cell population, or do you think that it perhaps could overcome some of the negative influences of ischemia, diabetes, and similar issues on stem cell engraftment and function?

Second, do you have any evidence from in vivo studies that this will be translated into a physiologic or potentially a clinical benefit?
Finally, how does this treatment potentially affect the phenotype of the cells or function of the actual cells, other than what you have described here?

Dr Coles. Thank you for those insightful questions. The first two seem to pertain to the in vivo effect of the cells, and we have not had the opportunity to transplant the CSs into a mouse model of severe combined immunodeficiency, for example, to see what happens to them in vivo, in terms of their differentiation, or their resistance to ischemic injury. We would predict that ILK gain-offunction, since it is a pro-survival gene, would tend to oppose ischemic damage to the cells.

The focus of this in vitro study was to identify the effect of this novel kinase on signaling in human cardiac progenitor cells and to try to understand the biology regarding ILK-mediated self-renewal versus differentiation. There is a lot more work to be done to try to nail down the signaling node elements in these progenitor cells that determine their phenotypic outcome.

One of the concerns, of course, is that ILK is an oncogene, so we would probably, in terms of ultimate clinical application, want to look for small molecule agonists of ILK rather than using the gene per se.

We do have something in our favor: Cardiac cells are inherently resistant to oncogenesis, so that we probably have some more latitude in terms of driving these cells to a pro-survival state.

Taken together, our data, although in vitro, indicate that ILK represents a novel and potentially useful target in cardiac progenitor cell signaling.

Dr Paul A. Kurlansky (Miami, Fla). Cardiomyocytes are under extreme control, not even in an ischemic situation but just in the regular situation. The regulation of stem cell development is obviously extremely tightly controlled. Do you have any insight as to how this promoter might interact with the control mechanisms that exist just in the normal adult heart?

Dr Coles. We know that ILK is present in normal cardiac tissue. Obviously, in these experiments, all we can conclude is that when you overexpress the gene, it tends to drive the cells into a self-renewal mode and/or to promote asynchronous division into terminally differentiated cardiac cells. Whether or not it is activated, let's say, in response to an endogenous myocardial damage signal, we do not know that in vivo. 